\title{
Rapid rural appraisal: rationale and repertoire $^{1}$
}

\author{
ROBERT CHAMBERS \\ University of Sussex
}

\section{SUMMARY}

Decision makers need the right information at the right time but in rural development much information generated is too costly and inappropriate. Rapid rural appraisal forms part of the attempt to learn about rural conditions in a cost effective way. Such appraisal involves avoiding the traps of quick and dirty or long and dirty methods and using instead methods that are more cost effective. To do this means ignoring inappropriate professional standards and instead applying a new rigour based on the two principles of optimal ignorance-knowing what it is not worth knowing-and proportionate accuracy-recognising the degree of accuracy required. The article reviews a range of approaches and techniques for rapid rural appraisal that are less rigid and exhaustive than many traditional methods and yet more rigorous in relation to cost and use. Time is emphasized as a critical factor in effective appraisal and rapid rural appraisal methods increase the chance of reducing the bias against the poorer rural people in the promotion of rural development.

\section{THE PROBLEM}

Decision-makers need information that is relevant, timely, accurate and usable. In rural development, a great deal of the information that is generated is, in various combinations, irrelevant, late, wrong and/or unusable anyway. It also often costs a lot to obtain, process, analyse and digest. Although many professionals have given thought to improving information gathering it remains a remarkably inefficient activity. Criteria of cost-effectiveness do not appear often to have been applied, and manifest inefficiency is sometimes met by demanding not better information, or less, but simply more.

The challenge is to find ways for outsiders to learn about rural conditions which are more cost-effective-which lead to information and understanding, which are closer to the optimal in trade-offs between cost of collection and learning, and relevance, timeliness, accuracy, and actual beneficial use. A recent workshop and conference on Rapid Rural Appraisal (RRA) ${ }^{2}$ have set out to examine this problem, paying particular attention to timeliness and economizing

Dr. Robert Chambers is a Fellow at the Institute of Development Studies, University of Sussex, Brighton, BN1 9RE, U.K.

'Earlier versions of this paper were presented to the World Bank Agricultural Sector Symposia in January 1980, and as Discussion Paper 155 of the Institute of Development Studies. University of Sussex.

'The Workshop on Rapid Rural Appraisal, 26-27 October 1979 (Barnett, 1979), and the Conference on Rapid Rural Appraisal, 4-7 December 1979, both at the Institute of Development Studies. University of Sussex. Appraisal is used here in its general sense and not just that of project appraisal. 
in data demands (Belshaw, 1979). This paper draws on the papers and discussions of those two occasions.

In the context of rural development projects, RRA appears especially relevant for identification and appraisal. Information is needed quickly; decisions are preempted by the passage of time. Commitment to projects and to details of projects sometimes becomes irreversible early on, setting a premium on timely information. But RRA is also relevant to implementation, monitoring and evaluation. Its relevance is enhanced by the view that rural development projects are not like construction works, with engineering blueprints which precisely predetermine what will be done, but rather like voyages into uncharted seas where direction and steering will change with new soundings and sightings. Techniques of RRA are hardly a new radar to prevent shipwreck; but they may at least reduce the dangers by showing more clearly and more quickly what is happening.

In practice, however, we seem to be trapped by two sets of inappropriate methods. These can be described as the 'quick-and-dirty' and the 'long-and-dirty', where 'dirty' means not cost-effective.

\section{QUICK-AND-DIRTY}

The most common form of quick-and-dirty appraisal is rural development tourism (Chambers, 1979a) - the brief rural visit by the urban-based professional. This can be very cost-effective with the outstanding individual; one example is Wolf Ladejinsky (1969a and b) who in two remarkable short field trips in India saw what was happening in the green revolution and reported it years before plodding social scientists came to the same conclusion to two (spurious) points of decimals. But more commonly, rural tourism exerts biases against perceiving rural poverty, reinforcing, in my view, underestimates of its prevalence and failures to understand its nature. These anti-poverty biases are:

(i) Spatial. Urban, tarmac and roadside biases. But the poorer people are often out of sight of the roadside, having sold out and moved away (Ssennyonga 1976; Moore 1979a) ${ }^{2}$ and otherwise tending to be concentrated in the regions remoter from urban centres.

(ii) Project. Outsiders link in with networks which channel them out from urban centres to those rural places where there are projects, where something, in short, is happening or is meant to be happening, to the neglect of non-project areas.

(iii) Biases of personal contact. Those met by rural tourists tend to be the less poor and the more powerful, men rather than women, users of services rather than non-users, adopters rather than non-adopters, the active rather than the non-active, those who have not had to migrate, and (inevitably) those who have not died. In all cases the bias is against perceiving the extent of deprivation.

\footnotetext{
2Thus Moore of one part of rural Sri Lanka: 'The proportion of houses with earth floors ranged from $14 \%$ in one locality to $40 \%$ in another. The remarkable fact is that one could drive along all the motorable roads in these localities and see scarcely a single mud floored house' (1979a).
} 
(iv) Dry season bias. In many tropical environments the wet season is the worst time of year especially for the poorer people (with hard work, food shortages, high food prices, high disease incidence, high indebtedness, etc. $)^{3}$ but urban-based professionals travel most in the post-harvest dry season when things are better.

(v) Biases of politeness and protocol. Courtesy and convention may deter rural tourists from enquiring about and meeting the poorer people. The rural tourist is also usually short of time and the poorer people stand at the end of the line.

Moreover, these biases interlock. The prosperity after harvest of a male farmer on a project beside a main road close to a capital city may colour the perceptions of a succession of influential officials and foreigners. The plight of a poor widow starving and sick in the wet season in a remote and inaccessible area may never in any way impinge on the consciousness of anyone outside her own community, and not all of them. The biases pull together towards those who are better off, and away from those who are poorer and more deprived.

Many of the other defects of quick-and-dirty investigations are well-known, but a list can serve as a warning:

(a) misleading replies: (deferential, prudent, hoping to avoid penalties or to gain benefits)

(b) failure to listen: (thinking the mouth is an organ of hearing)

(c) reinforced misperception and prejudice: (those old hands who 'know-it-all' but who are projecting and selecting their own meanings)

(d) visible as against invisible: things and activities are seen, but not relationships-indebtedness, interest rates, low wages, patron-client relations, intra-family relations, etc.

(e) snapshot, not trend: a moment in time is seen, and trends, which may be much more significant for rural development purposes, are not seen.

The list could be lengthened, but the point is made: quick appraisal can be seriously misleading, especially when there is a concern with the poorer people. Rapid is often wrong.

\section{LONG-AND-DIRTY}

The solutions preferred by many well-trained professionals are longer and more costly. Social anthropologists perpetuate their ritual immersions in alien cultures; sociologists and agricultural economists plan and perpetrate huge questionnaire surveys; and scientists map soils, vegetation, land use and rainfall. All have their uses but most of them do not generate much information in their early stages. ${ }^{4}$ Some are academically excellent but useless: the social anthropologist's

\footnotetext{
${ }^{3}$ For detailed analysis, see the papers of the Conference on Seasonal Dimensions to Rural Poverty, held at the IDS. University of Sussex. 3-6 July 1978, summarized in Chambers et al. (1979). See also Longhurst and Payne (1979) and Chambers (1979b).

${ }^{4}$ There are exceptions, especially in natural resources surveys.
} 
fieldwork published ten years later; the detailed soils map which sits on the shelf; the social survey which asked questions which were 'interesting' but of no use to a planner. Others are never processed: the extensive questionnaire survey with the 30 pages of questionnaire (multi-disciplinary, each discipline with its questions), which if asked are never coded, or if coded never punched, or if punched never processed, or if processed and printed out, never examined, or if examined, never analysed or written up, or if analysed and written up, never read, or if read, never understood or remembered, or if understood or remembered, never actually used to change action. Rural surveys must be one of the most inefficient industries in the world. Benchmark surveys are often criticised (Chambers, 1974; Clay, 1978; Conlin, 1979), and yet these huge operations persist, often in the name of the science of evaluation, preempting scarce national research resources, and generating mounds of data and papers which are likely to be an embarrassment to all until white ants or paper-shredders clean things up.

Some investigations are long and clean. The point here, though, is that long, however respectable professionally, is often inefficient. Moreover, the longer research takes, the longer and less usable the report tends to be and the greater the time available for sweeping the dirt under the carpet. Often the useful information from social anthropologists and from extensive questionnaire surveys comes coincidentally and informally during fieldwork, and not through the formal process at all.

\section{FAIRLY-QUICK-AND-FAIRLY-CLEAN}

The question is, then, whether there is a middle zone between quick-and-dirty and long-and-dirty, a zone of greater cost-effectiveness. People in many disciplines and professions have been converging on this question, but may have been deterred from writing it up because the activities are not quite proper. They have a sense of responsibility to their professional training or more crudely they have been brainwashed by their professional conditioning and reward systems. And yet in natural resources and environmental appraisal (Abel and Stocking, 1979; Belshaw, 1981; Richards, 1979; Stocking and Abel, 1979), health and nutrition (Chen, Chowdhury and Huffman, 1978; Gordon, 1979; Pacey, 1979; Payne, 1979; Walker, 1979), appraisal for agricultural research (Biggs, 1979; Byerlee et al., 1979; Carruthers, 1979a; Collinson, 1979; Hildebrand, 1979a) and the field of socio-economic stratification (Honadle, 1979; Howes, 1979b; Longhurst, 1979)-in these fields and others there is an active search for shortcuts with trade-offs between timeliness, accuracy, relevance and actual use of information.

Formidable obstacles impede this process and this convergence. In the words of one participant at the RRA conference; 'By the time people leave university the damage has been done.'; inappropriate professional standards have been imparted and internalized. Perhaps the biggest single blockage is the hegemony of statisticians (Carruthers, 1979b; Fallon 1979; Ellman, 1979; Moore, 1979b) and the failure to treat statistics as servant rather than master. In addition, professional values and reward systems deter improvisation in learning about 
rural conditions which though cost-effective may not seem pure. Better, it is thought, to be long and legitimate than short and suspect.

But cost-effective has its own rigour and should generate its own values. Two linked principles can be suggested:

(1) Optimal ignorance. This refers to the importance of knowing what it is not worth knowing. It requires great courage to implement. It is far, far easier to demand more and more information than it is to abstain from demanding it. Yet in information gathering there is often a monstrous overkill.

(2) Proportionate accuracy. Especially in surveys, much of the data collected has a degree of accuracy which is unnecessary. Orders of magnitude, and directions of change, are often all that is needed or that will be used.

With these two principles in mind, it is easier to see that less rigid, less exhaustive, and more rapid methods of rural appraisal may often be more rigorous in relation to cost and use. The following emerging repertoire of approaches and techniques is only part of a beginning. If much of this is common sense or common practice, I hope the reader will not feel insulted but rather will be provoked into criticism, comment and constructive suggestions for additions and improvement.

\section{A START WITH A REPERTOIRE FOR RRA}

What methods are best depends on purpose and circumstances. Some general principles can, however, be suggested:

(a) Taking time. RRA will avoid the tyranny of strict sampling, of the formal questionnaire, of the massive survey-in vain if time saved is dissipated in rushing. Many of rural tourism's defects come from haste.

(b) Offsetting biases. Taking thought about biases (urban, tarmac, roadside, project, elite, male, user, dry season, etc.), and deliberately offsetting them.

(c) Being unimportant. Avoiding the limousine-best-village-garlands-speeches syndrome.

(d) Listening and learning. Treating rural people as teachers and being their pupil. Assuming that they have much valid knowledge that outsiders do not have. Trying to get inside their skins and see the world as they do. Being open to unexpected information.

(e) Multiple approaches. Investigating the same questions with different methods, both to cross check and to fill out the picture.

From the papers and discussions so far, ten disparate techniques for RRA stand out. This list is far from complete, but it illustrates some of the range and possibilities.

\section{(i) Existing information}

There is often a wealth of information in archives, annual reports, reports of surveys, academic papers, government statistics, and the like. There is also a recurrent tendency to ignore them and to start de novo. Time spent searching for such information, even when it is not known to exist, is often well repaid; and it may save unnecessary demands for much new data collection. 


\section{(ii) Learning ITK (indigenous technical knowledge) ${ }^{5}$}

Development disasters often follow from failing to learn from rural people. The Groundnut Scheme might have been prevented by more time on the ground (instead of in the air) asking local inhabitants why they did not cultivate in the proposed project area. More radically, rural people often have a wealth of knowledge, and a validity of insight, which the outsider lacks. The Hanunoo in the Philippines are said to have had, on average, a knowledge of 1600 names for plants, 400 more than those in a botanical survey (Howes, 1979a, citing Conklin, 1957). The !Kung San of Botswana have a knowledge of animal behaviour often superior to that of scientists (Blurton Jones and Konner, 1976). Examples could be multiplied. Knowledge of soils, seasons, plants, domestic and wild animals, farming practices, diet, cooking practices, and child care, not to mention social customs and relations-are often rich and likely often to be superior in some or all respects to those of the outsider. The scope for soils mapping using ITK appears largely unexplored. The scope, on the social side, for asking rural people themselves to identify who are the poorer people, has been far from adequately used. Heavy survey expenditures could sometimes be reduced dramatically through using ITK instead of inappropriate 'sophisticated' approaches.

\section{(iii) Using key indicators}

Some indicators integrate several variables. Investigating, calibrating, observing and counting such indicators may then provide a shortcut avoiding more expensive, direct and time-consuming investigations.

Some examples are:

(a) Soil colour as a predictor of particle size distribution, fertility, some important engineering properties such as plasticity and volumetric activity (Stocking and Abel, 1979), and vegetation associations.

(b) Plant indicators, subject to local knowledge, can be 'an extremely reliable, efficient and rapid indicator of natural resources information' (Stocking and Abel, 1979).

(c) Birth weight of children reflects the health and nutritional status of mothers especially in the last trimester of pregnancy and is a predictor of chances of survival and (though less well established) of the future growth trajectory (Philip Payne, personal communication).

(d) Housing as an indicator of poverty or prosperity. There are no doubt qualifications and exceptions, yet this is found again and again (see e.g. Richards, 1978; Holıalde, 1979; Longhurst, 1979; Howes, 1979b; Moore, 1979a) and may be useful (not least because so visible and easy to count) as a proxy for relative poverty or prosperity between villages and for the same village over time.

${ }^{5}$ For six articles on this, see IDS (1979). In this paper, I am treating ITK simply as a resource to be tapped. This ignores its capacity for development and growth, and its importance as a dynamic entity enabling people to control their environment and enhance their quality of life. 
(e) Transfers and turnover in organizations may be a proxy for organizational capability.

While these and other indicators require local validation, they may provide shortcuts to insights; some may also provide simple measures for baselines if before-after evaluation is required, avoiding massive data collection.

\section{(iv) Adaptations of Hildebrand's 'sondeo'}

Peter Hildebrand, working with ICTA ${ }^{6}$, has developed an ingenious method for multi-disciplinary work in preparation for on-farm agricultural research (Hildebrand, 1978; 1979a and b). A homogeneous cropping system among many farmers in an area has first been identified. Hildebrand then takes a team of five agricultural scientists and five social scientists to the area for a week. The team works in pairs, one agricultural scientist and one social scientist. They go out each day and learn what they can from farmers and others, returning in the evening to share experiences, take stock, and decide on further priorities. Each day the pairs change so that each agricultural scientist works for one day with each social scientist and vice versa. A report is written over the weekend. This is 'not a benchmark study with quantifiable data that can be used in the future for project evaluation; rather it is a working document to orient the research program ...' (Hildebrand, 1979a).

Hildebrand's method has been used to familiarize staff with an area in which they are to work, and to identify innovations which might be tried out directly with farmers. It is easy to see that it might be adapted for other purposes. For project identification and appraisal, visiting teams might pair with themselves or with local officials. For monitoring and evaluation, it might be used to identify what changes have taken place and their causality. In principle, it might be applied in many fields, including natural resources appraisal (including rural people as sondeo team members), health and nutrition, and social and economic dimensions. ${ }^{7}$ It provides a structure for mutual learning between disciplines, and its time-bound form and the mutual checking in the evening sessions provide a stimulus for speed and accuracy.

\section{(v) Local researchers}

Information can be gathered by rural residents. The use of cultivators and pastoralists (Swift, 1978) for investigating and recording is underdeveloped. School teachers, traders, and the rural staff of government departments are a major, but often underused, source for information, including time series data and ad hoc enquiries. The value of research carried out by national university students also deserves to be emphasized. In a matter of a few weeks, a Murundi refugee student in Zaire investigated fishing among Barundi refugees and produced an excellent and practical report. A student who has links with a rural area can be not only key informant but can also very quickly and efficiently find out what needs to be known.

\footnotetext{
${ }^{6}$ Instituto de Ciencia y Tecnologia Agricolas, Guatemala

${ }^{7}$ It might complement very nicely the Benor Training and Visit System of Agricultural Extension.
} 


\section{(vi) Direct observation}

A major danger with RRA is being misled by myth. Rural people (like others) often have beliefs about their values and activities which do not correspond with the reality. It is common to be told about a custom, but probing for the last occasion when it was practised reveals that it has either lapsed or perhaps was never practised at all. Conlin records (1979) how he worked as a social anthropologist in an area in Peru where a sociologist carried out a survey. According to the sociologist's results, people invariably worked together on each others' individually held plots of land. This is what people told him. The belief was important to their understanding of themselves as a certain sort of people. Yet in one year's residence in the village, Conlin only observed this practice once. With RRA, direct observation may often not be possible; in that case, multiple checks on information about customs and practices are desirable. The importance of walking, seeing and asking questions is a commonplace. One of the most effective, though time-consuming, ways of learning is by doing. John Hatch hired himself out as a labourer to farmers and found the labour requirement of maize cultivation to be 50 per cent higher than that recorded in surveys (Hatch, 1976) besides learning much else from his farmer teachers.

\section{(vii) Key informants}

While there are well-known dangers, and cross-checking is necessary, key informants are a major tool for RRA. Some of the most useful are social anthropologists who are in the field. They often do not know what they know; they often give precious insights and raise unexpected questions. Key local informants tend to be the better off, the better educated, and the more powerful. The biases this introduces can be consciously offset; and school teachers, in particular, can be a source of somewhat independent-minded views. In organizational appraisal. Honadle (1979) asked staff a question on the lines: 'In all organizations there is at least one pain-in-the-neck, there is always someone who disagrees with all decisions and promotes trouble. Can you tell the names of those people in your association?' Answers were immediate and enthusiastic; individual interviews with those named provided valuable cross-checks and revealed useful additional information. More generally, for any subject of interest, it is worthwhile spending time asking who, or which group of people, are most knowledgeable, and then working with them.

\section{(viii) Group interviews}

Group interviews have several advantages, including access to a larger body of knowledge, and mutual checking. They can also be seriously misleading when the questioner is believed to have power to control benefits or sanctions. They are especially useful for natural resources information, when a wider geographical area and subject matter can be covered than with one respondent. I have used this method for very rapid mapping of soil/vegetation associations in the North-East Province of Kenya. Group interviews may also be good for certain sensitive types of information. To ask, for example, about land quality may arouse suspicion in an individual that his land may be subject to some 
penalty if he replies truthfully, whereas a group gathered together as people knowledgeable about farming will not feel so threatened (Jackson et al., 1978). Ladejinsky records of a landlord in Bihar: 'He first informed us that he owned 16 acres of land but corrected himself under the good humoured prodding of a crowd of farmers that he had failed to mention another 484 acres. The lapse of memory might have had something to do with the ceiling on land-holdings ...' (1969b). Group interviews have also been used to gather information rapidly on changes in infant feeding practices. Small clusters of 5-6 women of 2-3 generations were assembled, and past, present and expected future patterns of infant feeding discussed. 'There was a self-correcting mechanism within the group because if one person put across an over-favourable picture of her own or her group's behaviour, a peer would give a more realistic observation. In cross-checking with other groups a high degree of uniformity of information was found' (Gordon, 1979).

\section{(ix) The guided interview}

The guided interview is probably a quite widespread but largely unreported activity. There is no formal questionnaire but a checklist of questions which the interviewer uses as a flexible guide. Ellman's (1979) two-page checklist devised for appraisal of a rural refugee situation in Africa, and Carruthers' (1979a) critical review procedure for on-farm interviews are examples of procedures for interviews without pre-set questionnaires, but with an agenda to be covered. Collinson (1979) has developed this approach with guidelines for discussion with farmers, in which not all points are raised with all farmers, but in which a composite picture is built up so that a scenario can be written. This is evidently an effective tool for diagnosing farming problems and opportunities in a matter of weeks, and can be used by investigators with a professional training but who lack extensive field experience.

\section{(x) Aerial inspection and surveys}

Jokes about experts in aeroplanes should not detract from the selective value of aerial inspection and surveys. Animals are most rapidly counted from the air (Swift, 1978). For certain types of natural resource surveys, there are advantages (Abel and Stocking, 1979), including offsetting urban and dry season biases. The danger is that aerial surveys become substitutes for other approaches, especially understanding and using indigenous technical knowledge. Ground control should usually, if not always, include learning from rural people.

Other points could be added to the repertoire; the use of informal transects (such as walking away from the road at right angles); rural innovators' surveys in which new practices are sought out; methods of establishing rapport, in which liquor so frequently figures ${ }^{8}$ in non-Muslim societies; one-day censuses of users of services (Walker, 1979) and linking RRA in with on-going 'long-and-clean'

\footnotetext{
${ }^{8}$ Thus Paul Richards, on failing to identify unasked questions 'Luck, persistence, a sixth sense and palm wine are potential antidotes, but palm wine is probably the best' (1978), and Marie Therese Feuerstein on rapport 'Good informal rapport can be established by moderate drinking, smoking, singing, and particularly dancing or the playing of a musical instrument' (1979).
} 
investigations or research, making use of what is already known. But, hopefully enough has been said to show that RRA has a battery of techniques, and to suggest that using combinations with care may be much more cost-effective for some purposes than either quicker or longer alternatives.

\section{CONCLUSIONS}

This illustrative list of techniques shows that RRA is no panacea. Much of it is merely organized commonsense, freed from the chains of inappropriate professionalism. But because it is often cost-effective compared with more conventional alternatives, it deserves to be accorded more attention, more prestige, and more coverage in professional writing.

For project preparation it may provide a battery of methods for improving the chances of being right, and of having information when it is needed. For monitoring and evaluation, it may provide ways into the difficult questions about impacts, trends and causality which are, or should be, the core of evaluation.

That there are dangers of superficiality and error needs no emphasis. The key to successful RRA is not avoiding superficiality and error, but controlling them, trying to achieve cost-effectiveness through optimal ignorance and proportionate accuracy.

Finally, the most critical factor remains time. RRA, by its sparing demands for information, should release time which can be used for checking, for identifying unasked questions, and for noting and pursuing serendipity. Above all, it should release time for more contact with, and learning from, the poorer rural people. In most investigations, whether quick or long, they are the residual category, the last in line, those who are not consulted, those whose problems are not articulated. Shortage of time compounds the interlocking biases which shut them out. More time can be used to let them in. If RRA, whatever its defects, were to enable rural appraisers to spend more time learning about and understanding rural poverty, then the choice, design and implementation of rural projects might shift over time so that the poor gained more. That may be the naive hope of an optimist; but at least it seems worth pursuing.

\section{REFERENCES}

RRA1 and RRA2 refer to the first and second workshops on Rapid Rural Appraisal held at the Institute of Development Studies, University of Sussex on 26-27 October 1978 and 4-7 December 1979. Details of the papers given at these workshops are available from the Secretary, Rural Group, Institute of Development Studies, University of Sussex, Brighton BN1 9RE, U.K.

Abel. N. and Stocking, M. (1979). 'Rapid aerial survey techniques for rural areas', RRA 2.

Barnett, A. (1979). 'Rapid rural appraisal: a personal view of the first IDS workshop', RRA 2.

Belshaw, D. G. R. (1981). 'Village viability assessment procedures in Tanzania: decision-making with curtailed information requirements', Public Administration and Development. 1,(1) 3-13.

Belshaw, D. G. R. (1979). 'Theoretical foundations of data-economising appraisal procedures, with applications to rural development planning', RRA 2. 
Biggs, S. D. (1979). 'Timely analysis in programmes to generate agricultural technologies', RRA 2.

Blurton Jones, N. and Konner, M. J. (1976). '!Kung knowledge of animal behaviour (or: the proper study of mankind is animals)', in Lee, R. B. and DeVore, I. (eds.), Kalahari Hunter-Gatherers: Studies of the !Kung San and Their Neighbors, Harvard University Press, Cambridge, Mass.

Byerlee, D. et al., (1979). 'On-farm research to develop technologies appropriate to farmers', paper presented at the Conference of the International Association of Agricultural Economists, Banff, Canada, September.

Carruthers, I. (1979a). 'A mental construct for unstructured on-farm interviews', see RRA 2.

Carruthers, I. (1979b). 'Breadth, depth or replications?-sampling problems with insufficient time, money or background', RRA 2.

Chambers, R. (1974). Managing Rural Development: Ideas and Experience from East Afica, Scandinavian Institute of African Studies, Uppsala.

Chambers, R., Longhurst, R., Bradley, D. and Feachem, R. (1979). 'Seasonal dimensions to rural poverty: analysis and practical implications', Discussion Paper 142, Institute of Development Studies, University of Sussex, February.

Chambers, R. (1979a). 'Rural development tourism: poverty unperceived', RRA 2.

Chambers, R. (1979b). 'Health, agriculture and rural poverty: why seasons matter', Discussion Paper 148, Institute of Development Studies, University of Sussex, December.

Chen, C., Chowdhury, A. K. M. A., and Huffman, S. (1978). 'Classification of energy-protein malnutrition by anthropometry and subsequent risk of mortality', International Centre for Diarrhoeal Disease Research, Bangladesh, December.

Clay, E. J. (1978). 'Direct and indirect methods of observation in rapid rural appraisal', RRA 1.

Collinson, M. (1979). 'Understanding small farms', RRA 2.

Conklin, H. C. (1957). Hanunoo Agriculture. A Report on an Integral System of Shifting Cultivation in the Philippines, FAO Forestry Development Paper No. 12, Rome.

Conlin, S. (1979). 'Baseline surveys: an escape from thinking about research problems and, even more, a refuge from actually doing anything', RRA 2.

Ellman, A. (1979). 'Cost effectiveness of rapid appraisal for rural project preparation', see RRA 2.

Fallon, P. (1979). 'Comments on Mick Moore's "Denounce the gang of statisticians, etc.", , see RRA 2.

Gordon, G. (1979). 'Finding out about child ( $0-5$ years) feeding practices', RRA 2.

Hatch, J. K. (1976). The Corn Farmers of Motupe: a study of traditional farming practices in Northern Coastal Peru, Land Tenure Center Monographs No. 1, Land Tenure Center, 1525 Observatory Drive, University of Wisconsin, Madison, Wisconsin 53706.

Hildebrand, P. (1978). 'Motivating small farmers to accept change', paper for the Conference on Integrated Crop and Animal Production to Optimize Resource Utilization on Small Farms in Developing Countries, Bellagio, 18-23 October.

Hildebrand, P. (1979a). 'Summary of the Sondeo methodology used by ICTA', RRA 2.

Hildebrand, P. (1979b). 'Comments about multidisciplinary team efforts', RRA 2.

Honadle, G. (1979). 'Rapid reconnaissance approaches to organizational analysis for development administration', Working Paper No. l, prepared under AID Contract No. DSAN-C-0065, Development Alternatives, Inc., 1823 Jefferson Place, N.W., Washington D.C. 20036

Howes, M. (1979a). 'The uses of indigenous technical knowledge in development', in IDS (1979).

Howes, M. (1979b). 'Stratifying a rural population: trade-offs between accuracy and time', RRA 2.

IDS (1979). 'Rural development: whose knowledge counts?', IDS Bulletin 10, (2), Institute of Development Studies, University of Sussex, February.

Jackson, C., Mandal, S. and Carruthers, I. (1978). 'Notes on rapid land ownership and management studies', RRA 1. 


\section{Robert Chambers}

Ladejinsky, W. (1969a). 'The green revolution in Punjab: a field trip', Economic and Political Weekly, 4, (26), June 28.

Ladejinsky, W. (1969b). 'The green revolution in Bihar-the Kosi area: a field trip', Economic and Political Weekly, 4, (39), September 27.

Longhurst, R. (1979). 'Assessing economic stratification in rural communities', RRA 2.

Longhurst, R. and Payne, P. (1979). 'Seasonal aspects of nutrition: review of evidence and policy implications', Discussion Paper 145, November, Institute of Development Studies, University of Sussex, November.

Moore, M. (1979a). 'Beyond the tarmac road: a (nut) shell guide for rural poverty watchers', RRA 2

Moore, M. (1979b). 'Denounce the gang of statisticians. Struggle against the sample line. Unite the researching masses against professional hegemony', RRA 2.

Pacey, A. (1979). 'Rural appraisal in sanitation programmes: a technology case-study', RRA 2.

Payne, P. (1979). 'Assessment of nutrition problems: what do we look at and what do we measure?', RRA 2.

Richards, P. (1978). 'Geography is a bottle of Heineken lager beer-How to be the most boring person in development planning and still get your facts wrong', RRA 1.

Richards, P. (1979). "Community environmental knowledge in African rural development', IDS Bulletin, 10 (2) 28-36.

Stocking, M. and Abel, N. (1979). 'Ecological and environmental indicators for the rapid appraisal of natural resources', RRA 2.

Ssennyonga, J. (1976). 'The cultural dimensions of demographic trends', Populi, 3, (2).

Swift, J. (1978). 'Notes on rapid rural appraisal in dry pastoral areas of West Africa', RRA 1.

Walker, G. (1979). 'Notes on rapid appraisal of the utilization of rural health care services', RRA 2.

Wood, G. (1979). 'The social and scientific context of RRA', RRA 2. 